\title{
Measurement of clinical nurse performance: Developing a tool including contextual items
}

\author{
Emin Kahya*1, Nurten Oral ${ }^{1,2}$ \\ ${ }^{1}$ Eskisehir Osmangazi University, Meselik Campus, Eskisehir, Turkey \\ ${ }^{2}$ Eskișehir Osmangazi Hospital, Eskișehir, Turkey
}

Received: November 7, 2017

DOI: $10.5430 /$ jnep.v8n6p112
Accepted: December 28, 2017 Online Published: January 20, 2018

URL: https://doi.org/10.5430/jnep.v8n6p112

\begin{abstract}
Assessment of nurse performance plays an important role in guaranteeing high quality clinic care to achieve desired patient outcomes. Many tools measuring nurse performance in clinical settings have different dimensions of nurse skills. The objective of this research is to develop and test a new performance assessment tool incorporating applicable task and contextual performance items to measure clinical nurse's performance. Thirty-eight performance items were derived from previously cited literature and some tools that were in use. A questionnaire containing all items under eight categories was designed to reveal the appropriateness levels of the items. It was distributed to 233 clinical nurses from different hospitals in one city, who were asked to score them on a seven-point scale. The results indicate that although clinical skill and professional skill are the most important categories, the most scored item is "Working systematically" (mean $=6.07$, s.d. $=0.89$ ) in contextual category.
\end{abstract}

Key Words: Nurse performance, Nursing competency, Task performance, Contextual performance, Tool

\section{INTRODUCTION}

Assessment of nurse performance plays an important role in guaranteeing high quality clinic care to achieve desired patient outcomes. The search for valid and reliable method to access the clinical performance of nurses has a long history and remains a matter of concern. ${ }^{[1]}$ One of the major difficulties in developing a desirable tool is to select items which provide the most accurate and representative description of effective nurse performance.

Competence and competency have been used in the literature to describe various clinical skills as related to nurses' performance, including quality of care and productivity. ${ }^{[2]}$ The relationship between these terms is unclear ${ }^{[3]}$ not only in nursing but also in other fields of health. Past studies ${ }^{[4,5]}$ have comprehensively explored the concept of these terms within nursing. Competence is defined as the ability to perform a task with desirable outcomes. ${ }^{[6]}$ Competence has been recognized as a core component of professional standards. ${ }^{[7]}$ It is an effective application of knowledge and skills. Performance is clearly concerned with demonstrated ability to do something, a method of measuring achievement of competency. The effectiveness of performance evaluations therefore depends on the competencies that are chosen.

In recent years, the measurement of nurse performance is one of the most attractive studies for nurse researchers. Fitzpatrick et al. ${ }^{[8]}$ emphasized that variety approaches have been explored nurse performance ratings evaluated by different raters using a questionnaire. In previous attempts to design performance evaluation tools, a variety of strategies to generate and validate the content domain have been adopted. ${ }^{[9]}$

*Correspondence: Emin Kahya; Email: ekahya@ogu.edu.tr; Address: Department of Industrial Engineering, Engineering and Architecture Faculty, Eskisehir Osmangazi University, Meselik Campus, Eskisehir, Turkey. 
Several researchers have either reported test results for the reliability and validity of an available tool with the application of a pilot study, or focused on the development of where items were produced from the literature and expert opinion. They developed a questionnaire using information from a literature review on the nursing behaviors. Each one consists of many items (criteria) categorized into some significant domains of nurse skills. It has been suggested that much more efforts should be exhibited to develop better tools.

Several tools have been developed to assess nurse performance. Each one had different definitions for each nurse skill. Meretoja and Leino-Kilpi ${ }^{[10]}$ concluded from the literature review that many were still at the beginning stage of development, and there was hardly any tool that provided a reliable and accurate measure of nurse performance. The discussion continues in the literature concerning the type of tool to assess nurse performance.

One challenge health care manager face is the evaluation of work performance. Underlying the challenge is the struggle for objective and fair work evaluations. ${ }^{[11]}$ An apparent confusion exists regarding how performance is distinguished from competence. ${ }^{[8]}$ Performance word (criterion) is a method of measuring achievement of competency. The reliability of the performance evaluation, basically, depends on the chosen competencies. The evaluation system is used for two critical purposes; (i) to justify wage increases linked to salary, rewards, bonuses and promotion, and (ii) to determine weak and strong behaviors of staff in a assessment period. The health organizations should support training programs to improve staff' deficient areas. Qualified and competent nurses provide high quality clinical care and then enhanced patients because skilled nurses are close to their patients and able to handle their needs. The basic problem is which criteria can be used to evaluate a nurse. The criteria vary from two to seven for each competency.

A tool is administered to nurses to elicit their task-related knowledge, skills and abilities where items are the measures of task oriented behaviors. When employees use technical skills and knowledge to produce goods or services through the organization's core technical process, they are engaging in task performance. ${ }^{[12]}$ During the last decade, an increasing interest at using contextual behaviors in especially manufacturing companies has been witnessed in the literature. This type of work behaviors includes such contributions as volunteering for extra-job activities, helping co-workers, co-operating with others to solve problems, generating new ideas to make things (tasks) better. These are the measures of contextual performance. The effectiveness of certain types of organizations is more dependent on individual members'

Published by Sciedu Press voluntary and co-operative actions instead of standardized rules and procedures. The works in these organizations are usually carried out by variety experts who possess high levels of skills and need to co-operate with each other. Nursing job is also one of this kind. Co-operative and voluntary actions are central to day-to-day nursing operations. Nurses should help other nurses who have especially heavy workloads. Interestingly, items in tools are limited to areas of nursing tasks to assess the effectiveness of a nurse. Any study considering contextual behaviors into a tool, and classifying such items into functional domains has not been found in the nursing literature.

In many nursing studies, ${ }^{[13-15]}$ new items have been produced for different aims. Robb et al. ${ }^{[1]}$ concluded from a critical review of the research exploring the measurement of nurses' clinical performance that despite a 40-year history of researching and developing an instrument for measurement of nurse performance, there is none that is universally accepted for this purpose. Researches to seek reliable and valid measures continue.

The objective of this study is to develop a new performance assessment tool including applicable task and contextual performance items to measure clinical nurse's performance. The study presents two essential contributions to related literature: (a) identifying applicable contextual behaviors (e.g. volunteering for the activities) to measure clinical nurse performance, (b) indicating the differences among clinical types for nursing skill requirements.

\section{REVIEW OF THE RELEVENT LITERATURE}

There are many studies investigating the performance items to assess clinical nurses and developing a tool together with key literature and expert opinion. Several studies have reported on research into the testing of a tool's validity and reliability implementing such a tool for clinically based assessment (e.g., Liou and Cheng ${ }^{[16]}$ ) and integrative reviews of the literature on nursing competency standards (recenlty, e.g., Robb et al.; $;^{[1]}$ Chiarella et al.; ${ }^{[17]}$ Yanhua and Watson; ${ }^{[18]}$ Halcomb et al.; ${ }^{[19]}$ Flinkman et al. $\left.{ }^{[7]}\right)$.

The "Slater Nursing Competencies Rating Scale" is a generic tool, designed to assess the quality of nursing care. Redfern et al. ${ }^{[20]}$ stated that it is a comprehensive tool of its time for assessing a nurse's performance during actual delivery of care to patients. The tool consists of 84 observable items arranged into six subsections: psychosocial individual, psychosocial group, physical, general, communication, and professional implications.

Schwirian ${ }^{[21]}$ used a factor analysis to develop the "Six Dimension Scale of Performance". The 6D Scale con- 
sists of 52 items grouped into six subscales: leadership (5 items), critical care (7 items), teaching/collaboration (11 items), planning/evaluation (7 items), interpersonal relations/communications (12 items) and professional development (10 items). ${ }^{[6]}$ It was extensively tested for validity and reliability. Chronbach's alpha as the reliability score was found less than 0.90 .

Timmreck ${ }^{[22]}$ investigated how hospitals assess work performance of employees and how their performance appraisal systems are managed in 47 small rural hospitals in the Western United States. The research findings showed that in some hospitals one purpose for conducting a performance appraisal was to increase quality of care. Performance appraisal process will not, itself, increase quality of care. Timmreck ${ }^{[11]}$ presented a summary comparative list of objective and subjective items (words) derived from performance appraisal forms in use in 47 western hospitals, as well as from leading management and health administration journals, and textbooks. In this list, some important items to be found higher frequency are accuracy, effective use of time, dependability, initiative, cooperation, planning, communication, job development, basic judgement, technical knowledge, teamwork, problem solving, delegation.

Fitzpatrick et al. ${ }^{[9]}$ developed a tool (the "King's Nurse Performance Scale") to measure clinical nurse performance by incorporating the "Slater Nursing Competencies Rating Scale", the literature and expert opinion. The tool was classified into seven groups. The tool was utilized to observe the clinical performance of senior student nurses $(n=99)$. Internal consistency using Cronbach's alpha coefficient (0.93) revealed a promising alpha for the total instrument.

Tzeng and Ketefian ${ }^{[2]}$ investigated hospital employers' perceptions on the extent to which the identified 21 nursing skills were desired for staff nurses in Taiwan's medical care industry. They showed that levels of nursing competencies varied depending on type of service and hospital.

At its February 1999 meeting, the ACGME ${ }^{[23]}$ (Accreditation Council on Graduate Medical Education) (www.acgme.org) endorsed general competencies for residents in the arias of patient care, medical knowledge, practice-based learning and improvement, interpersonal and communication skills, professionalism, and system-based practice. Various tools to measure a trainee's progress with 25 items (required skills) have been described in ACGME toolbox. 360 degree evaluation instrument is one of the tools listed. Higgins et al. ${ }^{[24]}$ applied a 360-degree (multi-source) performance appraisal system produced from the ACGME tool. Three experimental dimensions were added as well: leadership of the patient care team, integrity, and patient-based learning and improvement.
Davis $^{[25]}$ conducted a project undertaken to determine whether the addition of peer, self, and nurse evaluators (360degree performance evaluation) would enhance faculty assessment of resident performance. An evaluation form, containing 16 items under three major headings; clinical competency, interpersonal skills, and overall assessment, was developed to evaluate resident nurses. This small study supported the use of peer evaluations in addition to attending evaluations for residents in training.

Carson ${ }^{[26]}$ investigated the characteristics of registered nurse performance appraisals in 87 hospitals offering general medical and surgical services and identified any evidence of inclusion of Watson's creative factors. The study attempted to determine whether there is any correlation between hospital size and inclusion of Watson's creative factors. The findings indicated little relationship between hospital size and Watson's factors, only second factor was statistically significant based on size.

A job evaluation (NHS JE-National Health Service Job Evaluation), pay (AfC - Agenda for Change) systems and also staff evaluation (KSF - Knowledge and Skill Framework) tool was developed by Department of Health (DH) in UK. The AfC pay system began to be implemented in twelve NHS organizations in England (see www.dh.gov.uk). The NHS KSF tool ${ }^{[27]}$ (http://www. nhsemployers . org) provides a means of recognizing the skills and knowledge that a person needs to apply to be effective in a particular NHS post. It consists of six core dimensions; "Communication", "Personal and people development", "Health, safety and security", "Service improvements", "Quality", and "Equality and diversity" and 24 specific items; "Health and well-being" (10 items), "Estates and facilities" (3 items), "Info and knowledge" ( 3 items), "General" ( 8 items). The tool was developed so as to assess all the staff in health organizations.

Park et al. ${ }^{[28]}$ developed the Clinical Competence Instrument used to evaluate Korean nurses' clinical performance and competence. It is available for use by members of the Korean Hospital Nurses Association. This instrument has a total of 30 questions divided into four subscales, including in "providing nursing care" (20 questions), "supporting patients" (3 questions), "communicating with patients and their families" (2 questions) and "attitudes towards nursing care" (5 questions). Kim et al. ${ }^{[29]}$ classified types of professional life quality of Korean nurses, and analyzed the relationship between demographic and professional characteristics and clinical competence.

Ko et al ${ }^{[13]}$ described a scale to measure nurses performance in the hospital setting. The scale consisted of 4 factors (competency, attitude, willingness to improve, and application 
of nursing process) and a total of 17 items. The study was conducted in three phases; a) an application of conceptual framework, b) development of items, c) test of validity and reliability of the scale. In order to test validity and reliability, data was collected from 1,966 nurses in twenty eight hospitals. Data analysis including descriptive statistics, factor analysis, and reliability coefficients was satisfied by the SAS 8.0 software.

Osman et al. ${ }^{[30]}$ developed a data envelopment analysis (DEA) model for nurse performance evaluation. The validity of the model was tested on thirty-two nurses in an Intensive Care Unit (ICU) at one of the most recognized hospitals in Lebanon.

Park and Lee ${ }^{[14]}$ developed a performance appraisal tool to assess the registered nurses in the neonatal intensive care unit (NICU). They identified 76 indicators classified into 4 domains of nursing: professional practice (49 items), responsibility of education (5 items), research (3 items) and leadership (19 items). Cronbach's $\alpha$ was 0.99 for all the items. This tool would be very to assess nurse performance and facilitate the professional growth of nurses.

Lee $^{[15]}$ developed a performance appraisal tool for postoperative anesthesia care unit nurses. Subsequent to a review of the literature on nursing performance of nurses, a questionnaire including 63 items was developed. Through factor analysis, items were derived in 3 domains with 8 factors: a) Professional nursing practice (31 items) (2 factors) (High frequency nursing practice, Low frequency nursing practice), b) Education \& Management (20 items) (4 factors) (Education \& communication, Management of drug \& equipment, Management of material \& safety, Management of infection) and c) Research \& Competency (12 items) (2 factors) (Research, Competency).

Taking into consideration a review of current literature, in this study, we decided to identify the following seven major criteria groups; professional skill, clinical skill, interpersonal communication, problem solving, professional ethic, teamwork, and leadership. Convenient items for the measurement of nursing performance were derived from the literature, reachable tools, and expert opinion.

\section{THE NATURE OF THE TASK AND CONTEX- TUAL PERFORMANCE}

Performance evaluation is the process that compares employees' job performance with job standards to measure how well the job is performed. There are two types of job performance: task performance and contextual performance.

Borman and Motowidlo ${ }^{[31]}$ defined task performance as "ac- tivities that contribute to the organization's technical core either directly by implementing a part of its technological process, or indirectly by providing it with needed materials or services". The task performance involves job related aspects that a particular employee is supposed to do at a given job. The job activities may include the quantity of work, quality of work done, speed of performing tasks, accuracy in work done and variety of the tasks being done or performed by the employee. ${ }^{[32,33]}$ Appropriate items to measure the efficiency of an employee depend on the nature of a job. In healthcare units, task performance is assessed by such items as "Managing nursing activities in time" and "Delivering well-prepared or careful nursing service to patient".

Werner ${ }^{[34]}$ indicated that contextual performance is individual efforts which are not directly related to their main task function but are important because they serve as a critical catalyst for task activities. Contextual performance including citizenship behaviour entails for activities other than core job and is mostly related to factors such as peers, work place and supervision. The activities such as helping and supporting peers at work place, showing keen and learning attitude towards assigned tasks, defending and obeying supervision available at work, doing tasks for others which are not one's responsibility, sharing of information and managing work and responsibilities willingly. ${ }^{[33]}$

Coleman and Borman ${ }^{[35]}$ settled these behaviors on three groups:

(1) Interpersonal citizenship: Behaviors include two subgroups.

i. Altruism: Assisting and supporting organization members such as "helping other organization members".

ii. Conscientiousness: Assisting and supporting employee performance through cooperation and facilitation efforts such as "Cooperating with other organization members".

(2) Organizational citizenship: Citizenship behaviors include two sub-groups.

i. Allegiance/Loyalty: Assisting and supporting the organization by demonstrating a personal commitment to the organization such as "Endorsing, supporting, or defending organizational objectives".

ii. Compliance: Confirming and adhering to the organizational rules, policies, and procedures, demonstrating impersonal behavioral commitment to the organization and organizational objective such as "Following organizational rules and procedures".

(3) Job/Task Conscientiousness (job dedication): Extra efforts that go beyond role requirements, demonstrating ded- 
ication to the job, persistence, and the desire to maximize one's own job performance such as "Putting extra effort on own job".

Although task performance traditionally has received more attention than contextual performance, researchers have be gun to empirically demonstrate that contextual performance yields a competitive advantage for organizations. ${ }^{[26]}$ Such helpful, considerate, and cooperative behaviors are expected to increase the effectiveness of workers, managers and work groups. They also improve organizational coordination by reducing friction among organizational members. Innovative and voluntary behaviors enhance organization's ability to solve unanticipated problems.

\section{METHOD}

\subsection{Aim}

The majority of manufacturing and service companies tend to add contextual behaviors to their own performance evaluation plan. Tools should focus on how nurses achieve nursing activities and perform extra-role behaviors including such contributions as volunteering for extra-role activities. The aim of this case study is to develop the applicable task and contextual performance items for a performance evaluation tool to assess direct care nurses' performance by managers in acute care clinical units.

\subsection{Tool}

The first stage of the study focused on a literature review regarding performance evaluation tools used in nursing to identify appropriate items for task performance. The items proving the most accurate and representative description of effective nurse performance in various clinical settings were derived from some cited studies ${ }^{[6,8,11,13,16,23,36]}$ and accessible tools (e.g. NHS KSF tool ${ }^{[27]}$ (www.dh.gov.uk)) and performance evaluation systems implemented by some hospitals in the country. The appropriateness of each item was discussed together with the experts from nursing management in a medical center. After an agreement, widely highlighted seventeen task-oriented items, which focused on enhanced patient satisfaction, and quality of care were identified to measure nurse performance, and classified into seven categories.

Thirty-one contextual performance items were generated from several studies ${ }^{[12,34]}$ and some applications. "Obeying cleanliness rules", which is widely used in health, food, and drinking industries, was also added to the tool. Eleven of them were included into contextual performance set, eight were entered into available task oriented categories, and the others were eliminated due to be less useful in effectiveness of nurse performance. The definition adjustments of the items were made for nursing sample to satisfy well understanding. As a result, a total of twenty-five task and eleven contextual items were proposed for the draft tool.

An open-ended questionnaire including all the items under 8 categories was designed to test the content validity of the tool. Second author of this study distributed the questionnaires to 34 supervisor nurses at one medical center, and they were asked to review the draft tool for clarity, commented on the tool's comprehensiveness, and suggested any other item that should be included in the tool. Twenty behavior items were suggested; 18 of them were combined with available one, and two new items, "Behaving in a friendly manner", and "calmness" were incorporated into the tool. A total of 38 items were selected for the tool. Some minor refinements of items wording to enhance readability were incorporated into the final version.

\subsection{Participants}

The participants in the second step were nurses, supervisor nurses in various units, representing medical, surgical, intensive care and emergency units, and nursing managers from one medical center, two regional hospitals, and two local hospitals in one city. The other health care organizations in the city except for the military hospital were either smaller-sized hospitals where the number of beds was less than 20 or were outpatient facilities. The sample population to participate in the study was nursing directors, all supervisor nurses, and one of each five nurses (randomly) in each unit. A total of 233 nurses were sampled from the target population.

\subsection{Data collection}

A questionnaire including demographic information (title, length of time in post and her unit-years-, education level), and 38 items under 8 category headings was designed to determine the appropriateness levels of the items. A cover letter explaining the purpose of the study and an instruction on how to complete was also attached to the questionnaire. Two students were engaged in distributing the questionnaires to participant nurses who were determined by second author. They were asked to rate each item in terms of the extent to how important each item is in their particular work environment on a seven-point scale from 1 (never required) to 7 (critical). A total of 195 questionnaires were returned, giving a response rate of $83.69 \%$, but 32 of them were excluded from the analysis due to missing data (no answer for more than half of the items) or inconsistency ratings (e.g., giving the same level for all items). All participants were female. The majority serves in her clinic as a nurse for more than 6 years. Their average lengths were $13.82($ s.d. $=6.73$ ) years for nursing experience and 6.85 (s.d. $=5.57$ ) years for

ISSN 1925-4040 E-ISSN 1925-4059 
clinical experience. The majority (104) had graduated from junior colleges.

\subsection{Ethical considerations}

The nursing management in each hospital approved the study. They were briefed about aim of the study and the procedures. Nurses were guaranteed confidentiality and anonymity, and return of a completed questionnaire was taken as consent to participate.

\subsection{Data analysis}

Statistical analyses were carried out using SPSS 24 statistical software for Windows. Data were first analyzed using descriptive statistics. A one-way analysis of variance (OneWay ANOVA procedure) and independent $t$-tests for equality of means were performed to investigate whether there were significant differences between the hospitals for each item. Scheffe's multiple comparison test (post hoc test) was run for comparing the difference between each pair of means with an appropriate adjustment ( $p$ values) for the multiple testing. In all the tests, the confidence level is $95 \%$. Multiple regression analysis was conducted to shed further lights, the relative contributions of the variables to nurse's preference. Four hierarchical regression analyses were established to allow for testing the incremental effects of the variables; in all steps, one of clinical experience was dependent variable, and four variables (title of nurse, education level, length of time in post-years-, and type of unit) were independent variables. The base model (Step 1) included the first variable (title of nurse). In each step, the other variable was entered to the previous step model. Such an approach reveals the effect of extended variable on preferences.

\section{RESUlts}

To test the reliability of the tool, Reliability Analysis was performed and Cronbach's alpha coefficients were found. All items showed high scale reliabilities, ranging from 0.72 to 0.87 as given in Table 1. Authors have suggested that an item with a coefficient alpha below 0.70 is considered for removal from the scale. The coefficients indicated that all items seem to be accepted. The reliability coefficient for all items together was 0.96. Kolmogorov-Smirnov's test for normality of the tool $(p>.12, \mathrm{z}=1.19)$ showed evidence of normal distribution of the data. These results supported the validity of the present tool. The most scored five items were, from high to low mean values, "Working systematically" $($ mean $=6.07$, s.d. $=0.89)$ in contextual category, "Solving speedy clinical problems" $($ mean $=5.94$, s.d. $=$ 0.91) in problem solving, "Monitoring patient's condition constantly and record his/her situation" (mean $=5.84$, s.d. $=0.97$ ) in clinical skill, "Confidentially" (mean $=5.83$, s.d $=0.93$ ) in professional ethic, "Identifying sudden changes related to patient's condition" ( mean $=5.75$, s.d. $=0.99)$ in problem solving (see Table 2).

Table 1. Means, standard deviations, reliabilities and correlations

\begin{tabular}{lllllllllll}
\hline Category & Mean & Std. Dev. & Reliabilities & $\mathbf{1}$ & $\mathbf{2}$ & $\mathbf{3}$ & $\mathbf{4}$ & $\mathbf{5}$ & $\mathbf{6}$ & $\mathbf{7}$ \\
\hline 1. Contextual & 4.81 & 1.06 & $.84-0.87$ & - & & & & & & \\
2. Professional skill & 6.04 & 0.79 & $.75-.80$ & $.311^{* *}$ & - & & & & & \\
3. Clinical skill & 6.14 & 0.85 & $.82-.87$ & $.216^{* *}$ & $.739^{* *}$ & - & & & & \\
4. Inter. communication & 5.60 & 0.90 & $.77-.83$ & $.322^{* *}$ & $.250^{* *}$ & $.236^{* *}$ & - & & & \\
5. Problem solving & 5.42 & 0.98 & $.76-.86$ & $.448^{* *}$ & $.342^{* *}$ & $.336^{* *}$ & $.538^{* *}$ & - & & \\
6. Professional ethic & 5.60 & 0.91 & $.72-.80$ & $.342^{* *}$ & $.384^{* *}$ & $.294^{* *}$ & $.404^{* *}$ & $.559^{* *}$ & - \\
7. Teamwork & 5.60 & 0.95 & $.80-.83$ & $.333^{* *}$ & $.228^{* *}$ & $.208^{* *}$ & $.372^{* *}$ & $.513^{* *}$ & $.586^{* *}$ & - \\
8. Leadership & 4.48 & 1.22 & $.75-.85$ & $.311^{* *}$ & $.169 *$ & $.159^{*}$ & $.209^{* *}$ & $.365^{* *}$ & $.211^{* *}$ & $.262^{* *}$ \\
\hline
\end{tabular}

Notes: $* * p<.01$ ( 2 -tailed), $* p<.05$ ( 2 -tailed)

Consistency of the items can be tested with a research whether an item is strongly correlated with other items. Correlation coefficient for any two items shows the degree of field superposition of an item. If a correlation coefficient is larger than a pre-specified value (e.g., $r>0.85$ ), it is suggested that two items, to a significant extent, are measuring the same field or requirement, which is defined as "multicollinearity". In this case, one of the items may be eliminated. When the matrix of correlation coefficients was achieved by using a SPSS Bivariate Correlation analysis, it was found that all the coefficients between the items were less than 0.80 .

Some statistical analyses were conducted on item categories. Descriptive statistics (means, and standard deviations), and Pearson's correlation coefficients among the item categories were reported in Table 1, which indicated several remarkable findings that should be noted. First, according to the nurses, clinical and professional skills were the most desirable items for assessing nurses. Interpersonal communication, profes- 
sional ethic, and teamwork had the same importance with As expected, professional skill was very highly correlated a score of 5.60. Second, from the correlation coefficients, with clinical skill $(r=.74, p<.01)$. There were modest professional ethic was significantly correlated with problem correlations between the categories, varying from $0.159(p<$ solving $(r=.559, p<.01)$ and teamwork $(r=.586, p<.01) . \quad .05)$ to $0.739(p<.01)$.

Table 2. Mean values of the items

\begin{tabular}{|c|c|c|c|c|}
\hline Dimension & Item & Mean & Std. dev. & Rank* $^{*}$ \\
\hline \multirow{11}{*}{ Contextual } & Being thrifty & 4.44 & 1.15 & 37 \\
\hline & Not complaining about organizational conditions & 5.34 & 1.12 & 24 \\
\hline & Not keeping others engaged in individual problems & 4.71 & 1.41 & 35 \\
\hline & Absenteeism & 5.69 & 1.05 & 8 \\
\hline & Participating in training meeting & 4.67 & 1.15 & 36 \\
\hline & Having a neat, clean appearance & 4.37 & 1.25 & 38 \\
\hline & Taking responsibility for the tasks. & 5.73 & 0.97 & 7 \\
\hline & Working harder than necessary & 5.74 & 0.99 & 6 \\
\hline & Working systematically & 6.07 & 0.89 & 1 \\
\hline & Engaging in self-development to improve own effectiveness & 5.36 & 1.03 & 23 \\
\hline & Obeying cleanliness rules & 5.54 & 1.00 & 17 \\
\hline \multirow{4}{*}{$\begin{array}{l}\text { Professional } \\
\text { Skill }\end{array}$} & Calmness & 5.69 & 0.97 & 9 \\
\hline & Keeping nursing equipment in good condition & 5.63 & 1.06 & 13 \\
\hline & Identify and assessing of the patient's problems & 5.51 & 1.10 & 18 \\
\hline & General Professional skill & 5.58 & 0.97 & 15 \\
\hline \multirow{6}{*}{ Clinical skill } & Planning patient care according to individual needs & 5.42 & 1.17 & 20 \\
\hline & Managing the nursing activities in time & 5.55 & 1.04 & 16 \\
\hline & Delivering well-prepared or careful nursing service to the patient & 5.62 & 1.03 & 14 \\
\hline & Monitoring patient's condition constantly and record his/her situation & 5.84 & 0.97 & 3 \\
\hline & Making an effort to enhance his/her well-being & 5.31 & 1.00 & 25 \\
\hline & Endorsing and following clinical rules, procedures and hospital policies & 5.15 & 1.06 & 29 \\
\hline \multirow{3}{*}{$\begin{array}{l}\text { Interpersonal } \\
\text { Communication }\end{array}$} & Expressing enthusiasm for nursing work & 5.39 & 0.99 & 21 \\
\hline & Cooperating with supervisor nurse & 5.46 & 0.98 & 19 \\
\hline & Behaving in a friendly manner & 5.65 & 0.98 & 12 \\
\hline \multirow{3}{*}{$\begin{array}{l}\text { Problem } \\
\text { Solving }\end{array}$} & Identifying sudden changes related to patient's condition & 5.75 & 0.99 & 5 \\
\hline & Solving speedy clinical problems & 5.94 & 0.91 & 2 \\
\hline & Taking initiative to solve a work problem & 5.29 & 0.96 & 26 \\
\hline \multirow{3}{*}{$\begin{array}{l}\text { Professional } \\
\text { Ethic }\end{array}$} & Attitude to patient and his/her family & 5.20 & 0.99 & 28 \\
\hline & Confidentially & 5.83 & 0.93 & 4 \\
\hline & Giving information to patient and his/her family & 5.21 & 1.04 & 27 \\
\hline \multirow{4}{*}{ Teamwork } & Cooperating with the members of other teams & 5.05 & 1.09 & 31 \\
\hline & Engaging responsibly in meetings and group activities & 5.69 & 0.99 & 10 \\
\hline & Giving feedback to colleagues in a constructive way & 5.66 & 0.94 & 11 \\
\hline & Engaging in and contributing to research-based practices & 4.90 & 1.03 & 33 \\
\hline \multirow{4}{*}{ Leadership } & Motivating other nurses & 5.04 & 1.05 & 32 \\
\hline & Coaching others in duties & 5.09 & 1.14 & 30 \\
\hline & Having a supervisor attributes & 4.89 & 1.11 & 34 \\
\hline & Helping to entry-to-practice beginning level nurses & 5.36 & 1.04 & 22 \\
\hline
\end{tabular}

* Rankings of mean values were ordered from high to low for all criteria 
The results in Table 3 show the differences among hospi- $=3.927, p<.05)$, and teamwork $\left(\mathrm{F}_{2,160}=4.407, p<.01\right)$; tals for nursing skill requirements. According to the values, however there was no significant difference for the others clinical skill and professional skill were the most important $\left(\mathrm{F}_{2,158-160}<2.000, p>.05\right)$. It is noticeable that such sigcategories for all hospitals except for the local hospitals. nificant differences in mean values reflect different needs There were significant differences between hospitals for pro- of nursing activities associated with these items in different fessional skill $\left(\mathrm{F}_{2,160}=3.987, p<.05\right)$, clinical skill $\left(\mathrm{F}_{2,159}\right.$ clinical environment.

Table 3. Mean scores for tool categories by hospitals and clinic types

\begin{tabular}{|c|c|c|c|c|}
\hline \multicolumn{5}{|l|}{ a. Type of hospital } \\
\hline Category & Medical Centre & \multicolumn{2}{|c|}{ Regional Hospitals } & Local Hospitals \\
\hline Contextual & 4.91 & \multicolumn{2}{|l|}{4.82} & 4.40 \\
\hline Professional skill & 6.23 & \multicolumn{2}{|l|}{5.95} & 5.75 \\
\hline Clinical skill & 6.35 & \multicolumn{2}{|l|}{5.97} & 6.00 \\
\hline Interpersonal communication & 5.58 & \multicolumn{2}{|l|}{5.55} & 5.85 \\
\hline Problem solving & 5.41 & \multicolumn{2}{|l|}{5.36} & 5.67 \\
\hline Professional ethic & 5.45 & \multicolumn{2}{|l|}{5.67} & 5.89 \\
\hline Teamwork & 5.35 & \multicolumn{2}{|l|}{5.82} & 5.60 \\
\hline Leadership & 4.32 & \multicolumn{2}{|l|}{4.61} & 4.53 \\
\hline \multicolumn{5}{|l|}{ b. Type of clinic } \\
\hline Category & Medical & Surgical & Intensive Care & Nursing Management \\
\hline Contextual & 4.93 & 4.70 & 4.85 & 4.44 \\
\hline Professional skill & 6.22 & 5.67 & 6.15 & 6.56 \\
\hline Clinical skill & 6.27 & 5.83 & 6.28 & 6.33 \\
\hline Interpersonal communication & 5.76 & 5.47 & 5.62 & 5.33 \\
\hline Problem solving & 5.64 & 5.23 & 5.46 & 4.89 \\
\hline Professional ethic & 5.75 & 5.41 & 5.68 & 5.44 \\
\hline Teamwork & 5.86 & 5.36 & 5.61 & 5.00 \\
\hline Leadership & 4.46 & 4.39 & 4.62 & 4.44 \\
\hline
\end{tabular}

In order to reveal the effect of clinic type on ratings, clinics were grouped into three categories: medical (7 clinics), surgical (12 clinics), and intensive care (10 clinics) units. The results (see Table 3) showed that the nurses from different clinics were affected from the clinical conditions when giving a decision. Professional skill and clinical skill were the most essential items for each of four type clinics, which was similar to former. The order of interpersonal communication (fourth), problem solving (sixth), contextual and leadership did not change. However, the next two differed from each other. Although professional ethic was much more essential for medical clinics and intensive care units, teamwork went to the fore for surgical clinics. Nursing top managers considered professional ethic as third important category. Nurses are expected to obey the ethic principles, especially. Professional ethic also was one of the first four categories in each clinic type. It is pointed out that these items has never considered among the most needed items in nursing literature. There was no significant difference between the means (all $p>.05$ ). In medical clinics, contextual behaviors, and professional skill oriented tasks were much more important. However, in intensive care units, clinical skill had the highest importance. For the other five categories, the mean scores were very similar to each other. Nursing managers are influenced less from clinical conditions; they decide in consideration with health policies of the hospital.

There are some halo effects on ratings of the raters, which is a threat to reliability of the assessment. The effect can be controlled with a regression analysis. Table 4 reports the results of multiple regression analysis including the standardized coefficient $(\beta), R^{2}, \Delta R^{2}$ (the change in $R^{2}$ ) for contextual item and $R^{2}$ for the others. The first column in Table 4 (Step 1) showed that the title of nurse $(\beta=-0.039, p<.05)$ was not a significant predictor on contextual performance. Nevertheless, it is accounted for $0.2 \%$ of the total variance $\left(R^{2}=.002\right)$, which is quite small. In all analyses (Step 1-4), the variable was predicted a negligible percentage of the variance. When 
education level was entered into regression equation (Step 2), the change in $R^{2}$ was $2 \%$. As predicted, education accounted for additional, significant variance in predicting contextual behaviors. It means that educated nurses tended to find contextual behaviors much more essential than the others. The length of time in post (years) was a statistically significant but negative predictor $(\beta=-174)$ (Step 3$)$.

Interestingly, experienced nurses judged that contextual behaviors did not have a significant effect on nurse performance. The results of the Step 4 indicated the most significant pre- dictors, which were experience and education level of nurse.

Table 4 ( $R^{2}$ for the other items) emphasized two noteworthy results. First, these four variables had an important effect on professional ethic and teamwork among the items. They accounted for approximately $11 \%$ of the total variance $\left(R^{2}=\right.$ .107 and $\left.R^{2}=.106\right)$. Second, the most significant predictors were experience and education level of nurse. The findings supported the literature ${ }^{[37]}$ which has noted that these factors have an impact on performance.

Table 4. Hierarchical multiple regression analyses

\begin{tabular}{|c|c|c|c|c|c|c|c|c|}
\hline \multicolumn{9}{|c|}{ a. The standardized coefficient $\beta, R^{2}, \Delta R^{2}$ for contextual items as dependent variable } \\
\hline \multicolumn{2}{|c|}{ Independent variables } & \multicolumn{2}{|l|}{$\beta$} & \multirow{2}{*}{$\begin{array}{l}\text { Step } 1 \\
-0.039\end{array}$} & \multirow{2}{*}{$\begin{array}{c}\text { Step } 2 \\
-0.075\end{array}$} & Step 3 & \multicolumn{2}{|c|}{ Step 4} \\
\hline Title of nurse & & \multicolumn{2}{|l|}{-0.054} & & & -0.007 & \multicolumn{2}{|c|}{-0.001} \\
\hline Education level & & \multicolumn{2}{|l|}{0.110} & & 0.147 & 0.157 & \multicolumn{2}{|c|}{0.157} \\
\hline Experience & & \multicolumn{2}{|l|}{-0.150} & & & -0.174 & \multicolumn{2}{|c|}{-0.169} \\
\hline Type of unit & & \multicolumn{2}{|l|}{0.054} & & & & \multicolumn{2}{|c|}{0.022} \\
\hline \multicolumn{4}{|l|}{$\mathrm{F}$} & 0.231 & 1.690 & 2.465 & \multicolumn{2}{|c|}{1.853} \\
\hline \multicolumn{3}{|l|}{ Significance } & & 0.631 & 0.188 & 0.065 & \multicolumn{2}{|c|}{0.122} \\
\hline \multicolumn{3}{|l|}{$R^{2}$} & & 0.002 & 0.022 & 0.047 & \multicolumn{2}{|c|}{0.047} \\
\hline \multicolumn{3}{|l|}{$\Delta R^{2}$} & & & 0.020 & 0.025 & \multicolumn{2}{|c|}{0.000} \\
\hline \multicolumn{9}{|l|}{ b. $R^{2}$ for the steps } \\
\hline $\begin{array}{l}\text { Independent } \\
\text { variables }\end{array}$ & \multicolumn{2}{|c|}{$\begin{array}{l}\text { Professional } \\
\text { skill }\end{array}$} & $\begin{array}{l}\text { Clinical } \\
\text { skill }\end{array}$ & $\begin{array}{l}\text { Interpersonal } \\
\text { communication }\end{array}$ & $\begin{array}{l}\text { Problem } \\
\text { solving }\end{array}$ & $\begin{array}{l}\text { Professional } \\
\text { Ethic }\end{array}$ & Teamwork & Leadership \\
\hline Title (Step 1) & \multicolumn{2}{|c|}{0.002} & 0.001 & 0.025 & 0.011 & 0.023 & 0.029 & 0.005 \\
\hline Education (Step 2) & \multicolumn{2}{|c|}{0.008} & 0.021 & 0.056 & 0.017 & 0.039 & 0.062 & 0.018 \\
\hline Experience (Step 3) & \multicolumn{2}{|c|}{0.023} & 0.037 & 0.078 & 0.045 & 0.102 & 0.104 & 0.020 \\
\hline Unit (Step 4) & \multicolumn{2}{|c|}{0.026} & 0.047 & 0.080 & 0.048 & 0.107 & 0.106 & 0.024 \\
\hline
\end{tabular}

Interestingly, while educated nurses predicted that interpersonal communication and teamwork had a significant impact, experienced nurses emphasized that professional ethic and teamwork were much more essential on nurse performance.

\section{Discussion}

This study reported developing and testing of a new performance evaluation tool including both task and contextual oriented items to assess nurse performance in clinical environment. It advanced the work of previous researchers in exploring the attributes of nurses prepared to meet both current and future demands of the healthcare organizations. The results indicated that clinical and professional skills categories had higher importance than the others. In several studies $^{[2,36]}$ where exploring and comparing the scores of competencies or items used to assess nurse performance, the first four items have been commonly pointed out among the most preferred skills. Our results were different but overlapped because of the fact that six of items took place in the most desirable ten items. Medical center had higher means than others in terms of clinical skill, professional skill and contextual, and the other means were not far from the highest. This result supported Tzeng's findings. ${ }^{[38]}$ Nurses working in medical center perceived that their jobs required more complicated skills than those nurses who worked in the other types of hospitals. In medical centers, care procedure is clearly defined and nursing knowledge is much more important than the others because of critical care activities. The order of interpersonal communication, professional ethic, and teamwork varied depending on type of hospital. While interpersonal communication, and professional ethic were much more important for the medical center, teamwork and professional ethic were the preliminary items for the regional hospitals. We can deduce from these results that the requirement level of an item, more or less, varies dependent on type of hospital (e.g. public/private, teaching/non-teaching, and etc.); some items can take much more dominant than the others.

Ours were different from items reported in existing litera- 
ture. To our knowledge, the tools developed for measuring nurse performance in the clinical settings become narrow, less addressed issues such as organizational and interpersonal citizenship behaviors, which are essential to quality of clinical care. The existing references or documents regarding nursing competencies only concern the functional elements of nursing tasks. They do not enable individual nurses to adopt well to new situations that are challenging them today, because they do not cover the fundamental personal attributes underlying excellent nursing performance. ${ }^{[36]}$ The present tool focused on enhanced patient satisfaction, in addition to these dimensions. The results confirmed the relevance of these issues that have begun to be much more important for a changing health care environment. Future research is needed to develop both the contextual and methodological areas of nurse assessment.

Similar studies describing the development of a performance evaluation tool for registered nurses in a healthcare organization were presented by Springer et al., ${ }^{[39]}$ Hader et al. ${ }^{[40]}$ and O'Hara et al. ${ }^{[41]}$ in addition to well known tools. The reliability scores of them were less than 0.90 . However, the coefficients of the items ranged from 0.72 to 0.87 . Certainly, this is not an evidence that the present tool is stronger than a popular one. For a comparison, the testing of the other in the same hospital settings is required. Although the number of items in the tool (38) was less than the numbers in the other popular tools (greater than 50), this alpha makes it a potentially useful performance evaluation tool. In addition, each had a mean value greater than 4 of 7 which indicates less difference in the ratings. The reliability of a tool may rise while increasing the number of items, but it gets difficult to provide specific evaluation of each behavior of all nurses in a unit for a rater (e.g. supervisor). The number of items of the tool was held less to enable to a reliable but easy-to-use tool.

In traditional performance evaluation systems, an employee is assessed by a manager. However, a manager doesn't know well some behaviors of employees and also rating have some halo effects. Especially in a health or service system, a multi-rater performance evaluation system, e.g. 360 degree feedback, provides an accurate and reliable result to assess nursing performance. It might be useful in evaluating professional behaviors, interpersonal and communication skills, as well as some components of patient care and system. A nurse in a service can be evaluated by self, peers, supervisor nurse, nursing director, doctors, and patients in a unit. The system decreases halo effect.

The major limitation to this study is the generalizability. The number of valid questionnaires was 163 , which was $23.87 \%$ of all the nurses in relevant clinics; this sample is significant Published by Sciedu Press for the city. The limitation is that the results may not be generalized to other countries. However, in terms of the scores, population is not a drawback; an item for a hospital can take higher importance than others. This is not a dilemma. It is not difficult to predict that both organizational culture such as mission, vision, and values of the hospital are effectual factors for selecting the items.

\section{Conclusion}

A variety of methodologies has been explored in attempts to measure and compare nurse performance including the use of rating studies. This study took into account the items undertaken with regard to the role of the clinical nurses. It is surprising that in terms of the scores, problem solving, although, was the sixth essential item, two of the highest items belong to problem solving category. Disappointingly, no study adopting contextual behaviors have placed in the relevant literature. However, the findings of this research highlighted the potential importance of these behaviors. Four contextual items were a part of the most essential ten items, which have been neglected at the other related investigations. In a humanistic work role such a nursing, being able to do a task is not in itself enough; posts are carried out by individuals who are able to contextualize care by respecting users' own values, cultural beliefs and approaches to health and ill-health.

The tool is able to measure nurse performance in a different health organization; its particular strength (overall $\alpha=0.96$ ) lies in its ability to measure overall nurse performance in the clinical settings. However, the subsection alphas indicated that further refinement may improve the strength of the tool for measuring nurse performance in different domains of practice. A measure set by adopting a task analysis methodology for a health setting is required in order to enhance both validity end reliability of the tool. Some items cancelled due to weak effect on nurse performance (e.g., reliability, doing something with patience, empathy, listening skill, and creativity) can become desirable for other health organizations.

In conclusion, applicable items to measure nurse performance are, probably, one of the biggest challenges for broads of nursing. Our findings addressed the current scope of nursing; nurses are higher accountable for professional ethic, professional problem solving, and interpersonal communication dimensions of nursing posts. In the next attempts to design a tool, it is expected that items linked to mission (what it wants to achieve), vision (the ideal image of the organization in the future), and values (e.g. respect to patients, honesty, etc.) of organization will be considered.

\section{CONFLicts OF InTEREST Disclosure}

The authors declare that there is no conflict of interest. 


\section{REFERENCES}

[1] Robb Y, Fleming V, Dietert C. Measurement of clinical performance of nurses: A literature review. Nurse Education Today. 2002; 22: 293-300. https://doi.org/10.1054/nedt.2001.0714

[2] Tzeng HM, Ketefian S. Demand for nursing competencies: an exploratory study in Taiwan's hospital system. Journal of Clinical Nursing. 2003 ; 12: 1-10. http://dx.doi.org/10.1046/j.1365-2 702.2003.00738.x

[3] O'Connor SE, Pearce J, Smith RL, et al. An evaluation of the clinical performance of newly qualified nurses: A competency based assessment. Nurse Education Today. 2001; 21: 559-568. https://doi.org/10.1054/nedt.2001.0594

[4] Lin CJ, Hsu CH, Li TC, et al. Measuring professional competency of public health nurses: development of a scale and psychometric evaluation. Journal of Clinical Nursing. 2010; 19(21-22): 3161-3170. http://dx.doi.org/10.1111/j.1365-2702.2009.03149.x

[5] Franklin N, Melville P. Competency assessment tools: An exploration of the pedagogical issues facing competency assessment for nurses in the clinical environment. Collegian. 2015; 22: 25-31. https://doi.org/10.1016/j.colegn.2013.10.005

[6] Meretoja R, Isoaho H, Leino-Kilpi H. Nurse competence scale: development and psychometric testing. Journal of Advanced Nursing. 2004; 47(2): 124-133. http://dx.doi.org/10.1111/j.1365-2 $648.2004 .03071 . \mathrm{x}$

[7] Flinkman M, Leino-Kilpi H, Numminen O, et al. Nurse Competence Scale: a systematic and psychometric review. Journal of Advanced Nursing. 2017; 73(5): 1035-1050. http://dx.doi.org/10.1111 /jan. 13183

[8] Fitzpatrick JM, While AE, Roberts JD. The measurement of nurse performance and its differentiation by course of preparation. Journal of Advanced Nursing. 1994; 20: 761-768. http://dx.doi.org/1 $0.1046 / j .1365-2648.1994 .20040761 . x$

[9] Fitzpatrick JM, While AE, Roberts JD. Measuring clinical nurse performance: development of the King's Nurse Performance Scale. International Journal of Nursing Studies. 1997; 34(3): 222-230. https://doi.org/10.1016/S0020-7489(97)00009-6

[10] Meretoja R, Leino-Kilpi H. Instruments for evaluating nurse competence. Journal of Nursing Administration. 2001; 31(7/8): 346-352. PMid:11519263 https://doi.org/10.1097/00005110-20010 7000-00005

[11] Timmreck TC. Developing successful performance appraisals thought choosing appropriate words to effectively describe work. Health Care Management Review. 1998; 23(3): 4857. PMid:9702561 https://doi.org/10.1097/00004010-199 802330-00006

[12] Van Scotter JR. Relationships of task performance and contextual performance with turnover, job satisfaction, and affective commitment. Human Resource Management Review. 2000; 10(1): 79-95. https://doi.org/10.1016/S1053-4822(99)00040-6

[13] Ko YK, Lee TW, Lim JY. Development of a performance measurement scale for hospital nurses. Journal of Korean Academy of Nursing. 2007; 37(3): 286-294. https://doi.org/10.4040/jkan. 2 007.37 .3 .286

[14] Park KO, Lee YY. Developing a performance appraisal tool for neonatal intensive care unit registered nurses. Journal of Korean Academic Society of Nursing Education. 2011; 17(2): 267-276. https://doi.org/10.5977/JKASNE. 2011.17.2.267

[15] Lee YY. Development of a Performance Appraisal Tool for Postoperative Anesthesia Care Unit Nurses. J Korean Acad Nurs Adm. 2016; 22(3): 270-278. http://dx.doi.org/10.11111/jkana. 2016.22.3. 270
[16] Liou SR, Cheng CY. Developing and validating the Clinical Competence Questionnaire: A self-assessment instrument for upcoming baccalaureate nursing graduates. Journal of Nursing Education and Practice. 2014; 4(2): 56-66. https ://doi.org/10.5430/jnep.v $4 \mathrm{n} 2 \mathrm{p} 56$

[17] Chiarella M, Thoms D, Lau C, et al. An overview of the competency movement in nursing and midwifery. Collegian. 2008; 15(2): 45-53. https ://doi.org/10.1016/j.colegn.2008.02.001

[18] Yanhua C, Watson R. A review of clinical competence assessment in nursing. Nurse Education Today. 2011; 31(8): 832-836 https://doi.org/10.1016/j.nedt.2011.05.003

[19] Halcomb E, Stephens M, Bryce J, et al. Nursing competency standards in primary health care: an integrative review. Journal of Clinical Nursing. 2016; 25(9-10): 2016. http://dx.doi.org/10.1111/j ocn. 13224

[20] Redfern S, Norman I, Calman L, et al. Assessing competence to practice in nursing: A review of the literature. Research Papers in Education. 2002; 17: 51-77. http://dx.doi.org/10.1080/026 71520110058714

[21] Schwirian PM. Evaluating the performance of nurses: A multidimensional approach. Nursing Research. 1978; 27(6): 347-351. PMid:251246 https : //doi .org/10.1097/00006199-1978110 00-00004

[22] Timmreck TC. Performance appraisal systems in rural western hospitals. Health Care Management Review. 1989; 14(2): 3143. PMid:2654071 https://doi.org/10.1097/00004010-198 921000-00005

[23] ACGME, ACGME (Accreditation Council on Graduate Medical Education) Outcome Project. Available from: http://www .acgme.org

[24] Higgins RSD, Bridges J, Burke JM, et al. Implementing the ACGME general competencies in a cardiothoracic surgery residency program using 360-degree feedback. The Society of Thoracic Surgeons. 2004; 77: 12-17. https://doi.org/10.1016/j.athoracsur.2 003.09 .075

[25] Davis JD. Comparison of faculty, peer, self, and nurse assessment of obstetrics and gynecology residents. The American College of Obstetricians and Gynecologists. 2002; 99(4): 647-651. https : //doi .org/10.1016/S0029-7844(02)01658-7

[26] Carson EM. Do performance appraisals of registered nurses reflect a relationship between hospital size and caring? Nursing Forum. 2004; 39(1): 5-13. https://doi.org/10.1111/j.0029-6473. $2004.00005 . \mathrm{x}$

[27] Simplified Knowledge and Skills Framework (KSF). Available from: http://www.nhsemployers .org/your-workforce/ret ain-and-improve/managing-your-workforce/appraisal s/simplified-ksf Last accessed December 2017.

[28] Park SA, Park KO, Kim SY, et al. A development of standardized nurse performance appraisal tool. J Korean Clin Nurs Res. 2007; 13: 197-211.

[29] Kim K, Han Y, Kwak Y, et al. Professional Quality of Life and Clinical Competencies among Korean Nurses. Asian Nursing Research. 2015; 9: 200-206. https : //doi.org/10.1016/j.anr.2015.03. 002

[30] Osman IH, Berbar LN, Sidani Y, et al. Data Envelopment Analysis Model for the Appraisal and Relative Performance Evaluation of Nurses at an Intensive Care Unit. Journal of Medical Systems. 2011; 35(5): 1039-1062. https://doi.org/10.1007/s10916-010-9 570-4

[31] Borman WC, Motowidlo SM. Expanding the criterion domain to include elements of contextual performance. Chapter in N. Schmitt and W. C. Borman (Eds.), Personnel selection in organizations (pp. 71-98). San Francisco: Jossey-Bass; 1993. 
[32] Edwards BD, Bell ST, Arther JW, et al. Relationship between facets of job satisfaction and task and contextual performance. Applied Psychology: An International Review. 2008; 57(3): 441-465. http://dx.doi.org/10.1111/j.1464-0597.2008.00328.x

[33] Tufail MS, Mahesar HA, Pathan SK. Organizational justice, task and contextual performance: empirical analysis for front line managers. Grassroots. 2017; 51(1): 269-281. Available from: http://sujo.usindh.edu.pk/index.php/Grassroot s/article/view/3262

[34] Werner JM. Implications of OCB and contextual performance for human resource management. Human Resource Management Review. 2000; 10(1): 3-24. https://doi.org/10.1016/S1053-4 822 (99) 00036-4

[35] Coleman VI, Borman WC. Investigating the underlying structure of the citizenship performance domain. Human Resource Management Review. 2000; 10(1): 25-44. https://doi.org/10.1016/S105 3-4822 (99) 00037-6

[36] Zhang ZX, Luk W, Arthur D, et al. Nursing competencies: personal characteristics contributing to effective nursing performance. Journal of Advanced Nursing. 2001; 33(4): 467-474. http://dx.doi.org /10.1046/j.1365-2648.2001.01688.x
[37] Drach-Zahavy A. Primary nurses' performance: role of supportive management. Journal of Advanced Nursing. 2004; 45(1): 7-16. http://dx.doi.org/10.1046/j.1365-2648.2003.02855.x

[38] Tzeng HM. Demand and supply for nursing competencies in Taiwan's hospital industry. Nursing Economics. 2003; 21(3): 130-139. PMid:12847987

[39] Springer P, Payne K, Petermann B. Rating nursing performance based on behaviors. Journal of Nursing Administration. 1998; 28(1): 3945. PMid:9451382 https://doi.org/10.1097/00005110-199 801000-00008

[40] Hader R, Sorensen ER, Edelson W, et al. Developing a registered nurse performance appraisal tool. Journal of Nursing Administration. 1999; 29(9): 26-32. PMid:10491666 https://doi.org/10.109 7/00005110-199909000-00007

[41] O'Hara NF, Duvanich M, Foss J, et al. The venderbilt professional nursing practice program, Part 2. Integrating a Professional Advancement and Performance Evaluation System. Journal of Nursing Administration. 2003; 33(10): 512-521. PMid:14551469 https: //doi.org/10.1097/00005110-200310000-00006 